\title{
Erratum to: Comparative Study of 1,064-nm Laser-Induced Skin Burn and Thermal Skin Burn
}

\author{
Yi-Ming Zhang $\cdot$ Jing Ruan $\cdot$ Rong Xiao \\ Qiong Zhang $\cdot$ Yue-Sheng Huang
}

Published online: 23 November 2013

(C) Springer Science+Business Media New York 2013

\section{Erratum to: Cell Biochem Biophys}

(2013) 67: 1005-1014

DOI 10.1007/s12013-013-9596-6

The authors would like to specify the Grant from National Natural Science Foundation of China correctly. The updated version of the acknowledgement is published with this erratum.

\begin{abstract}
Acknowledgments This work was supported by the National Program on Key Basic Research Project of China (973 Program; 2012CB518101), a Grant from National Natural Science Foundation of China (81101436) and a Grant from 1130 Project of Xinqiao Hospital.
\end{abstract}

The online version of the original article can be found under doi:10. 1007/s12013-013-9596-6.

Y.-M. Zhang · J. Ruan · R. Xiao · Q. Zhang · Y.-S. Huang ( $₫)$

Institute of Burn Research, Southwest Hospital, State Key

Laboratory of Trauma, Burns and Combined Injury, Third

Military Medical University, Chongqing 400038,

People's Republic of China

e-mail: yshuang.tmmu@gmail.com

Present Address:

Y.-M. Zhang

Department of Plastic and Cosmetic Surgery, Xinqiao Hospital,

Third Military Medical University, Xinqiao Road, Sha Ping Ba

District, Chongqing 400037, People's Republic of China 